\title{
Disrupting Pathways of Intergenerational Transmissions of Gender Ideology and Practice
}

\author{
Mariz Tadros
}

\begin{abstract}
This article examines pathways to intergenerational transmission of gender values, norms and ideology with a particular focus on contexts where there is a strong intersection between gender and poverty. The first part explores the multiplicity of conduits of knowledge and influence across generations. The potential for reversing the direction of intergenerational influence and challenging its unilinearity are further examined in a study of a project supporting child leaders in Egypt. The article explores the opportunities and challenges in facilitating children's agency in poor communities and argues that although they were able to challenge social values on various levels, their agency was limited by structural factors. The last section examines some of the structural dynamics associated with the demise of the gender contract (in practice but not in ideology) on intergenerational transmission of values and ideas, and how they may bring possibilities for disruptions in gender ideas and values, both positive and negative.
\end{abstract}

\section{Challenging the focus on conventional conduits and direction of intergenerational gendered transmission}

The study of intergenerational transmission (IGT) of knowledge, values and ideas encounters a number of challenges. First, there is the challenge of recognising the multiplicity of actors and knowledge sources that influence the conveyance of gendered roles and hierarchies. In other words, the study of socialisation of children by parents is important, but often there are other conduits of influence which have displaced parents or have traditionally been more important or because children are exposed to a multiplicity of other sources and are more affected by them (or choose to selectively filter those they interact with most). Second, there is the need to recognise the fluidity and, indeed, ambivalence characterising such transmissions. Third, there is the challenge of going beyond a unilinear understanding of such transmissions, which assumes that members of the younger generation are always the object of transmissions and never agents of influence in their own right. One model of the study of pathways of IGT of values suggests that there are three pathways: vertical transmission, involving transmission between generations within a family; horizontal transmission, referring to influences exerted by peers; and oblique transmission, referring to transmission from members of the previous generation other than parents. While vertical transmissions of gender values are important, there are many contexts in which horizontal and oblique transmissions are equally or even more influential in shaping the nature and content of transmission of values and ideas.

In one study of transmission of values among Turkish immigrant families settled in Germany, an attempt was made to compare the content of the transmission of values from parents to children and the extent to which the new generation conformed to the values of their parents. The study suggested that parental socialisation goals function in part as mediators of intergenerational value transmission. For example, it was noted that 'Turkish fathers have higher aspirations for the school career of their sons than mothers have for their daughters'. However, the study also revealed that despite their parents' differential aspirations, in reality, 
'daughters themselves are not less aspiring than sons' (Phalet and Schönpflug 2001: 500). The study does not offer a detailed explanation to account for this; however, it does suggest that the direction of causation may work both ways: a girl's school success may be cause for family pride and the better educational prospects for a girl may increase her aspirations as well as those of her parents. In the first instance, agency becomes important: it is not automatic that a girl's aspirations would be reflective of her parents'values; in the second, it suggests how context (educational opportunity) can impact on the effects of socialisation.

Evidence from other case studies also suggests that children and adolescents are influenced by knowledge sources that extend beyond the family as conduits of information. For example, in a study on cross-generational knowledge transfer on reproductive health issues in Ghana, the role of the grandmother as the conduit of information between parents and children was historically important, because it was the means through which mothers influenced generational transmission of knowledge. This knowledge tended to be more on the level of instruction, moralising and socialisation (Greenstreet and Banibensu 1997: 65). However, 'modernity has tended to subvert the established rapport between the first and third generation'. Instead, young girls tend to receive their information from schools and peers as they scorn their grandmothers' knowledge as outdated and irrelevant. One of the implications of the rupture of the grandmother-child relationship is that the strong bond between the three generations seems to have become weakened, creating a social distance (Greenstreet and Banibensu 1997: 67). Only a third of all women in the study discussed reproductive issues with their daughters, regarding these issues as taboo topics and claiming that they are too shy to discuss such matters with their daughters. Yet the disruption of the IGT of traditional knowledge by education, technology, new lifestyles or economic hardship has not provided alternative conduits for knowledge that address information gaps and silences on critical issues affecting young girls through their life-cycle (Greenstreet and Banibensu 1997: 71). While the subversion of the system has led to resistance to patriarchal control over women, on the other hand, important silences remain which have not been broached.
In another study on IGT of knowledge in a remote Punjabi village in Pakistan, it was also observed that young girls' access to knowledge on women and gender-related issues tends to be more likely transmitted through the sister-in-law or elder sister than through the mother (Mumtaz and Rauf 1997: 110). Mumtaz and Rauf suggest that the transmission of knowledge in the area of sexuality tended to be shrouded in silence and also tended to be intragenerational as well as intergenerational. In this particular context, 'neither mothers nor grandmothers appear as major transmitters of knowledge on menstruation and sex'. Rather, it is the sisters and young married women of the immediate family who provide information at the outset of a girl's transition from childhood to womanhood (marked by menstruation, which is then followed by purdah, wearing of the burqa and preparation for marriage). Friends and married sisters-in-law give indirect information on sex at the time of marriage (Mumtaz and Rauf 1997: 117).

\subsection{Children as unconventional agents of change}

Interviews with children who participated in a leadership programme in Egypt revealed that the most influential sources of knowledge on a variety of issues, including gender-related ones, were peers at school, friends in the neighbourhood and teachers in addition to parents. ${ }^{1}$ In some cases, they identified most with the values of their peers rather than their parents. Samer, ${ }^{2}$ a 13 -year-old boy, and Sherifa, a 14-year-old girl, who come from a rural community, were among the children who participated in the leadership programme. Samer spoke of how his father was always a strong advocate of girls' right to education like boys and how he strongly defended girls' right to reach the highest levels of education among his friends, peers and neighbours. Samer explained that his father sought to instil these ideas among his three daughters by reminding them that 'education is the weapon you hold in life, your education is [just as important as it is for your brothers], it is what will protect your rights when you grow up'. Samer also spoke of how his mother always reminded him that while girls can get married and live securely, an uneducated man brings shame to the whole family. Yet he was more accepting of his peers', friends' and teachers' ideas. 'Most of my friends [boys] at school saw it as eib [socially and morally wrong] for girls to get an education even if their own sisters were attending the same school.' The 
behaviour of the teachers, Samer said, also reflected their lack of conviction of the equal rights of girls and boys to education:

They used to encourage us [boys] more and they would be very pleased when one of us boys did well or got full marks but we didn't notice they were as happy when one of the girls topped the exam. When we did not get high grades or when some of the girls got high grades some teachers would say to us 'it is a catastrophe [moseeba] when a girl can pass and get full marks and you men are not able to'. Also, if a girl solves a maths problem, they would tell us: 'see, for sure, you can solve it too, if a girl could do it, surely, you could do too'.

His friends in the neighbourhood also had an impact on his own opinions:

The boys we played with in our street used to say that girls who get an education are not morally upright ... and there were a lot of rumours being passed around about girls from our village who went to the city to finish their education [university] and the boys would say these girls become morally corrupt and go around with boys and they would say no respectable man from a good family would ever marry a girl who is educated, especially those who were educated outside our village.

Samer held on to the belief that girls' pursuit of education undermined their 'reputation' and, hence, was socially inappropriate, especially when it was neither necessary nor important.

Sherifa, aged 14, from the same village, also spoke about how her own ideas on girls' education were influenced by ideas and opinions other than those of her parents.

\section{I come from a poor family and my mother and my} father don't see the importance of education for girls if you can secure a good marriage, like my eldest sister who was engaged to my cousin and there was no point in her getting educated because my cousin was well off and he did not need her to work or anything like that.

She grew up with a different view - with the idea that education for girls is important, but that beyond a certain point, it could be detrimental (that is, it may affect her chances of getting married because it would be a sign of 'excessive' independence). Such an idea may have been influenced by her teachers at school, who emphasised the role of education for preparing girls for motherhood.

\subsection{Catalysing change: processes of personal transformation in children's agency}

Sherifa and Samer participated in a programme designed to promote children's rights in poor marginalised communities by enabling them to become influential advocates of change on children's rights, including gender-related ones, in their communities. The programme, which was funded by Swedish International Development Cooperation Agency (Sida) and implemented by Al Karma Television Company cum Development Agency with Plan International Egypt worked in 12 communities. The idea behind it was to identify children below the age of 15 in each local community who were willing to participate in the programme. The children participated in an intensive leadership and coaching programme on a variety of children's rights. Some of the key questions arising from their experience of involvement were: When and how did they feel change? What kind of change and on what level? Reflections from the children suggested that their exposure and participation in unconventional and informal pedagogical experiences were key to catalysing a process of personal transformation. One essential aspect of this pedagogical encounter from the perspective of many children was their experience of being listened to. This space to being recognised as individuals with their own right to speak out, discuss, contest and reflect as equals, rather than their previous experiences of being recognised only as repositories for the older generation's inculcation, was very significant.

Other activities followed through which sought to create legitimate space and roles for the children in the community. The first was mobilising support from among peers: each child was encouraged to form his or her own group (shella) among other children to create a team that would lead the change process in their community. In order to facilitate access to resources and spheres of influence, the implementers sought to embed these teams in local non-governmental organisations (NGOs) where they could initiate activities and seek to mobilise support for their community-level initiatives. However, it seems to be a constellation of factors that together catalysed the process of their assuming the role of change agents: participatory learning and engagement, support through mentoring, embedding the issue of gender equality in education in a wider 
framework relating to children's rights (in other words, there was no gender expert parachuting in to proselytise on the subject). Samer confides that his views on the issue of gender equality in education changed - he doesn't know exactly when - but he remembers it was sometime during the above mentioned process.

\section{My position changed. Before, I didn't care much whether girls got educated or not, and I considered the topic a bit of a joke and used to make fun of girls who got educated, and now I have a different view. I would like to participate in projects whatever their goal, whether the education of girls or the education of boys and that the two should have the same opportunities.}

The real change came for him when he realised that equality among all children necessitates that discrimination against girls' access to education be removed. He also came to the realisation that there is a need to go beyond the notion of education being a means to secure a good marriage for a girl.

I learnt that education is a basic necessity not something through which to secure a girl's future so even if my sister were rich and could guarantee a good marriage education is still important for her and building her character and more importantly, it is a basic right for her exactly like it is for me.

As Samer formed his own shella and worked with his peers, he believed he had a role to change the social values of parents and children regarding children's rights in education: 'I also learnt that the discrimination between girls and boys has to do with social values and beliefs and that changing them is difficult and that I with my group of children leaders can change the reality in which we live'. Samer was able to mobilise change not only in attitudes but also in behaviours among his group. He noted that the boys from his group who used to verbally harass girls on the streets, in school or at the local NGO have stopped doing that and treat them with more respect. He also points out that whereas before girls and boys hardly ever mixed, and were very uncomfortable in each other's presence, the girls and boys in his group feel confident enough to talk to each other and relate to each other with respect.

Sherifa also spoke of how through the mentoring and training process, she began to critically reflect on her own experience of the messages she was exposed to through her educational process: 'our teachers used to sometimes encourage us girls to get an education and this used to make us happy', However, after participating in the programme she thought differently:

\section{I realised that what I was hearing from the teachers was not right, because it is not compatible with the idea of a girl's right to full equality with a boy in education, so for example, the teachers would say to us 'girls you must get educated and protect yourselves with education because education is very important for you so that you know how to raise your children properly'. I learnt that this kind of talk affirms that I am not equal to boys because it means that education for us is not a basic right but only a means through which to raise children. So what if one of us God does not bestow with children or does not get married, would that mean that education is not necessary for her?}

Sherifa felt that as she became more confident about her own views on education, she became able to articulate that message better among her peers. Through the work she undertook with her group and through the local NGOs, she was able to formulate strong arguments reflecting her convictions. While she admits that her mother is not entirely convinced 'with this whole business of children's rights', she was able to bring a change not only in her father's attitude but his behaviour as well. Although her father was not against the idea of a girl's right to education, like other fathers he followed socially acceptable norms of behaviour for girls such as not travelling outside the village without one's family. Her father was so affected by the transformation that had happened to her and her new role as a local leader that he allowed her that extra margin of freedom to travel outside her village to participate in conferences and trainings. Consequently, claiming leadership emerged both from children realising their own sense of self, reflecting on their own experiences and the kind of inculcation they have been exposed to, and from the deliberate efforts to create (and sometimes force) space for them to exercise leadership in the community.

\section{Widening the impact of change: from the personal to the communal}

While the children were becoming more conscious of their personal agency and the new spaces opening up for exercising this, nonetheless 
they were also conscious that their spheres of influence were quite limited. Most children who participated in the programme noted that whatever change they could catalyse in attitudes or behaviours were mostly at the level of their peers or families. The local communities did not take them seriously until they started appearing on national television - and from then on, the potential for influencing the wider community became real. The second part of the programme involved intensive training on television writing and production. Children became involved in producing their own episodes on human rights violations in their local contexts and which have national resonance. Examples include corporal punishment at school and female genital mutilation (FGM). These amounted to the production of episodes by Al Karma, each episode featuring a series of short segments presented by the children themselves, who prepared the script (with assistance) and conducted interviews on the issue at hand. For example, one segment might feature two children interviewing a doctor and a religious leader on FGM. Another might feature interviews with girls and boys who perform nontraditional gender roles in their homes and communities. These episodes formed the television programme Esmaouna (Listen to Us), which began to be broadcast on the most important national channel, Channel One, on prime-time television on Friday mornings, a time when a significant proportion of families are at home (the weekend) and often relaxing in front of the television before preparing for the Friday prayers. In a country where 99 per cent of all households have access to television, it proves to be a powerful outreach tool. (According to one independent study on the programme's outreach, Esmaouna reaches 96 per cent of urban and 94 per cent of rural households containing families with children.)

While the initial training gave the children the knowledge and skills to work on children's rights, it was their appearance on prime-time national television that served to give their voices legitimacy, credibility and even political weight in the community. These children appeared on national television interviewing highly influential government decision-makers and nongovernmental activists and leaders. Given that national television is state-owned and -controlled in Egypt, programmes aired on national television tend to be viewed by the highest ranks of the policymaking apparatus in the government. The very fact that they were interviewing high-ranking officials in the actual episodes (contacts facilitated by Al Karma network of connections) gave the semblance to local communities that they actually had access to these people. This challenged the power hierarchy in the local community where only an elite segment of the population could claim connections with the decision- and policymakers, and even then, these connections were with people not as senior and influential as those interviewed by the children. For example, the local headmaster started taking seriously these children's demands for changes in school policy and practice when he saw them interviewing on television officials who ranked only second to the Minister of Education.

The extent to which this model of supporting children's agency is replicable is questionable (how many children can you give access to primetime television in a weekly episode of half an hour?). There are also issues regarding its sustainability: how do you sustain the legitimacy the children have gained in the eyes of their families and communities when they are no longer on air?

Yet the process of enabling children to claim leadership in local communities is pertinent because it challenges conventional ideas about the nature and impact of generational transmission of gender-related ideas in highly traditional settings. These were children who were able to influence values and ideas of older generations and, in some cases, prompt them to change practices and behaviours that are discriminatory (not only on the basis of gender but age as well). There are multiple ways of creating an enabling environment for children to assume leadership roles and to become agents of change on issues that are important to them. For Sherifa and Samer, appearing on television was that key factor: 'Since we appeared on television, we have become important people and we have noticed that the teachers and even the headmaster treat us differently. We have become famous.' The village, pointed out Sherifa, was conscious that through these episodes, they would be communicating to a very large audience. The impact on the villagers of having their own children being 'watched by all of Egypt' was far reaching. The fact that the 
episodes tackled real life issues through real life stories and interviews made them not shrug them off as just 'presenting the imaginary stuff that movies are made of'. It is ironic that in order to gain legitimate voice in the local setting, they had first to be recognised on the national level. They had to show that they had access to power that the village did not have.

\section{The limits of children's agency: structural impediments on a micro and macro level}

Though it was a powerful medium for challenging conventional pathways and directions for IGT of gender roles, values and power hierarchies, television was not a magic bullet for transforming practice and behaviours in these communities. Children's experiences as agents of change varied from one context to another, but even more so, on the nature of the topic tackled and the extent to which they can tap into repertoires of support and facilitation. In contexts in which they engaged with people who did not witness the transformative impact of their appearance on television in their village, they were not so 'big'. For example, in many of the smaller villages, teachers instructing them at school were not locals and often did not live in the same community. They were not conscious of the ways in which these children had gained legitimacy as local leaders. The greatest challenges they met, however, were in broaching topics that touched on deeply embedded value systems, cherished by the community, and for which they were not backed sufficiently by support people and institutions. For example, what facilitated the work of Samer and Sherifa on gender equality in education in their village was that the local NGO gave them the space, backing and resources to engage with the community. Supported by members of the NGO who themselves had solid reputations and spheres of influence, the children's work did not meet significant resistance - at least in terms of the message they were delivering.

However, in another village, the dynamics were very different when the children decided to launch a campaign against FGM and prepared a play on the topic that was performed at the local NGO (and which then became an episode of Esmaouna). The girl, a local leader, who acted the role of the child who had undergone female circumcision, was subject to a scathing attack by some of her teachers at school. They told her she was impolite to raise an issue like that and had loose morals, and she should be punished. Given that teachers occupy a high status in local communities and have the power to jeopardise the academic careers of children at school, it is no wonder that the girl in question broke down and was traumatised. It took the intervention of many other parties (including other children leaders seeking the involvement of the headmaster) to deal with the implications of this incident. Similarly, in the same village, another girl, also a local leader, who had participated in the play on FGM was subject to a vicious attack by her neighbour, who also made accusations of immorality.

When asked what would enable them to have a greater impact in their communities, Sherifa mentioned that while parents may be convinced about the importance of educating girls, dire economic circumstances and the rise of the costs of education are likely to affect girls' dropout rate. Supporting children to assume leadership roles and to become agents of change in local contexts may go a long way in challenging conventional beliefs and values, breaking taboos and creating a new dynamic in the community where they engage with a different agenda - one formulated and led by children. Yet the transformative power of their agency is limited by structural factors, which require nationallevel policy change (i.e. making education propoor) as well as reducing poverty on local and national levels. In other words, the IGT of human capital may require more than a change of values regarding parents' ideas on and aspirations for girls' education.

\section{Structural and social impediments to transforming gendered hierarchies and values intergenerationally: agency in the context of poverty}

Moore's (2001) study of IGT of poverty provides a useful conceptual framework for examining the gendered nature of the process and the allocation of resources. Moore identifies different forms of capital (human, sociocultural, sociopolitical, financial/material and environmental/natural) that affect the intergenerational process and the transfer, extraction and absence thereof of such forms of capital. What is relevant here is the gendered nature of IGT of human capital. As has been observed in many contexts, the incentive to keep children at school becomes even weaker when the rewards of education are uncertain. In 
the context of Egypt, the level of unemployment increases with the level of education attained (e.g. unemployment rates are lowest among those who are illiterate and highest among middle degree holders and university graduates). Hence, even if children convince parents of the importance of education from a rights perspective, in practice translating this into reality becomes problematic in the face of strategic choices. On the other hand, parents may find strategic ways of providing their girl child with an education (from a rights point of view) without actually keeping their children at school. In the urban squatter settlement of Bulaq el Dakrour, many mothers pointed out that faced with girls who were not performing so well in school and in the light of the excruciating expenses, they decided to remove them from school, wait until they are 12 and enrol them in literacy classes which are free and which allow them to continue their education through home schooling.

Moreover, some forms of capital - such as social capital - are not easily transferable across generations. Unlike land, which is inherited as a physical/financial capital, social capital is not so easily 'inherited'. Children's agency in local communities (as in the Esmaouna programme) cannot influence the way in which social capital is transmitted. Children who participated in Esmaouna were able to influence their community through the social capital they themselves generated during the course of the programme (with highly influential members of the community: headmasters, NGO focal points, local government officials, etc.). However their repertoire of social capital cannot be passed on to the next generation, nor can their own parents or families tap into it. The limitations of IGT of social capital are important in contexts where gender and poverty intersect. Much of the literature on poor women's coping strategies describes the strategic importance of social capital in the form of networks and connections for their survival and that of their families. However, there are 'rules' for social capital transaction. The importance of reciprocity for social capital, which Putnam (1993: 172) emphasises, means that people select members to be part of their social networks based on perceived estimates of their ability to reciprocate favours. It means that those with the fewest assets and the fewest connections are most likely to be excluded from thriving social networks.
For example, 22-year-old Rida is a young woman who lost her mother and became the breadwinner of her household. Since both their parents died, she has been supporting herself and her 14-year-old sister, Azza. Her brother, Ahmad, is 16 and supports himself. They all live in a one-bedroom accommodation. Her father abandoned them a few years before, remarried and never visited. He died in 1999. One year later, their mother who supported them also passed away. Ahmad managed to find work but will not contribute to the household. Rida and Azza receive an orphans' pension of LE50 ( 44.50$)$ from the Ministry of Social Solidarity. In addition to this meagre sum, Rida works as a salesgirl at a shop for LE120 (£11) a month. For Rida, her mother's death has devastated her family. She finds it ironic that they used to receive more assistance when their mother was alive and working than today, when they are poorer than ever before. For her, assistance is about connections and she does not have her mother's network. Her mother used to sell home-made falafil and baqlawa and used this to build up her steady source of clients and connections. She also built up a hefty debt, as she was continually purchasing items on shukuk [credit, paid in instalments] for her two daughters' dowries. Rida is still paying back these instalments, although she has been forced to sell most of it to manage her day-to-day living. Rida believes that they have been marginalised since their mother is no longer alive. They still get a monthly LE5 $(£ 0.45)$ from one of the local charities but nobody tells them when additional assistance is being distributed by the organisation. She also gets LE20 (£1.80) a month from another charity association. She has heard of a mosque that gives assistance but is scared that she would need a wasta [connection] to be put on its payroll. Rida claims she receives no assistance from family or relatives, although some better-off individuals from the neighbourhood have assisted her privately. Rida's predicament undermines Dordick's suggestion that the social capital of the poor is 'the one asset they can potentially draw upon to help negotiate their way through an unpredictable and unforgiving world' (Woolcock 2002: 26). She was not able to 'inherit' her mother's expansive network of connections.

It is significant that access to some forms of social capital (e.g. connections with charity-disbursing NGOs) may be helpful for day-to-day survival; 
however, the social stigma they bear may also have long-term implications on women's wellbeing. For example, Rida points out that in most cases she does not go herself to receive the monthly handouts from the local charity organisations but rather sends her younger sister to collect them. Rida justifies this on the basis that her sister is still 'a child' and hence her reputation would not be affected by undertaking these errands. On the other hand, for herself, Rida confided with pain 'I am worried that if I am seen seeking assistance from the mosques/charity organisations, no one will want to marry me. Going to the mosque for assistance involves stretching out your hand'. Yet Azza also confided that it feels awkward for her to go to these organisations herself and she is always worried what people think of her. This was the sentiment that many adolescent girls interviewed shared: this sense of embarrassment about receiving handouts from local charity organisations, even when they did not have to go themselves. They felt angry that their mothers 'have to beg' in these charities to feed them, and their awareness that if word comes out, they may be scorned and ridiculed by their peers, or worse, deter future marriage partners (who wants to marry a woman whose mother begs from one charity to the next? This is the kind of message they fear). It is true that poor women would use their social capital to access financial capital because, in many cases, women are the ones who are given the responsibility of seeking assistance from various charities (because it is considered too demeaning for men, and because in some cases, even charities with patriarchal mindsets recognise that women are more likely than men to spend the money on the children). As a day-to-day survival mechanism, women may tap into their social capital with local charities; however, it often bears a price for the children in terms of its impact on their marriage prospects and social mobility.

The pressure on women to rely on a supposedly non-exhaustive repertoire of social capital becomes particularly problematic in the light of the demise of the gender contract. In the conventional gender contract, the gender division of roles between men and women was constructed on the premise that men were the producers and women the reproducers. In such a model, men were the breadwinners. However, due to high unemployment rates, men in many contexts are finding it increasingly difficult to find waged employment or employment whose remuneration is sufficient to cover daily expenses. Survival strategies for women to provide for their families in such circumstances include seeking employment, relying increasingly on charity and seeking assistance from their extended families, neighbours and friends. It is significant that while the gender contract has in practice been dissolved, ideologically it is still very salient. Although men are no longer able to provide single-handedly for their households, ideologically social values, ideas and beliefs still reflect it.

The implications for IGT of values and ideas pertaining to gender roles are significant. One case in point is that of Fillipina mothers leading transnational female-headed households in different countries. There is a growing body of literature on the emergence of 'female-headed transnational families' - families in which the core members are living in at least two nationstates and in which the mother works in another country. The Philippines is, 'one of the largest sources of independent female labour migrants in the world and there is a growing number of female-headed transnational families'. The impact of their 'mothering from a distance' on the intergeneration bond with their children has been extensively documented by Parrenas (2001). These have strained mothers' own perception of their roles as well as those of the children who also purport to them. Parrenas notes that
three central conflicts plague
intergenerational relationships between migrant mothers and children whom they have left behind in the Philippines. First, children disagree with their mothers that commodities are sufficient markers of love. Second, they do not believe that their mothers recognise the sacrifices that children have made toward the successful maintenance of the family. Finally, although they appreciate the efforts of migrant mothers to show affection and care, they still question the extent of their efforts, and say that family is more important than money, possibly because they are talking in contexts of financial security. (Parrenas 2001)

What accentuates the pain is that the reality of households' reliance on women's external remittance for survival does not conform to the dominant gender ideology with regards to the expectations of motherhood. Homes in which 
mothers are away are depicted as broken and abnormal. This is projected on mothers' own guilt and sense of inadequacy as mothers for failing to be there for their children. It also features in the child's perception of the extent to which their mother has fulfilled her parenting role towards them, especially when compared to the father. For example, in households where fathers were the ones to leave in search of employment, it was perceived as painful but necessary for the family's financial welfare and for the father's fulfilment of his role as provider. On the other hand, while some children understood why their mother was away, Parrenas notes, they feel that her primary role should have been to take care of them and they should have perhaps sought an employment opportunity locally. Parrenas argues that 'the reconstitution of gender ideologies in the family would not lessen the sacrifices of children in transnational families but would temper the pain of separation', and that they would come to appreciate more their mother's 'reconstituted form of emotional care from a distance'. They would not, for example, expect mothers to be solely responsible for both the material and emotional welfare of the family.

The demise of the gender contract - in practice but not in dominant ideology - may have longterm implications for disruptions in intergenerational gender dynamics. Would mothers insist that their daughters marry men who are able to provide for them so as not to share their mothers' predicament? On the other hand, would it be possible that in the light of the limited opportunities for men to provide for women, the emphasis on equipping women to stand on their own two feet would be greater, thus breaking the cycle of sustaining the ideology behind the conventional gender division of labour? In addition, the intergenerational dynamics within families may also be significantly affected by the demise of the gender contract. Would it mean that men become increasingly reliant on financial assistance from their parents? Would that increase the power of intervention of the mother-in-law? Alternatively, if a man's parents cannot assist financially, would it increase the wife's family's intervention? The implications for disruptions in the conduit and content of intergenerational values, including those relating to gender have been largely unexplored. What does it mean for the IGT of gender values? Would there eventually be forms of resistance against the ideology behind the gender contract itself? These issues are still largely unexplored.

\section{Conclusions}

Intergenerational transmissions are gendered in multiple ways. The conduit of knowledge is often a reflection of power hierarchies and social organisation, which have a direct impact on the kind of role models, values and ideas relayed. The Esmaouna project has raised some important questions relating to disrupting gendered IGTs. First, children identified multiple conduits of knowledge which influenced their ideas and values relating to gender roles. Second, children's agency catalysed a process of reversed transmission of knowledge intergenerationally, from children to older generations. The process proved to be dynamic, non-static and non-unilinear. In some cases, children could claim success as agents who catalysed a process of open discussion of taboo issues. In other cases, they were able to effect behavioural change, especially among their peers. The Esmaouna project highlighted the possibility of opening avenues for children articulating their voices and setting their agenda locally through unconventional means. Personal transformation was often elicited through an alternative pedagogical experience. The informal educational component included giving the space for children to reflect, voice their concerns and issues and be listened to. It also involved exposing children to a wide variety of sources of knowledge, ideas and practices than they had access to previously. The informal educational experience also involved working with mentors and coaches on developing leadership skills and community mobilisation. The programme was unconventional and distinct from the traditional educational system they were accustomed to in terms of approach to learning, content of learning and the conduits of knowledge-sharing and reflection.

Another opportunity that greatly facilitated their assumption of leadership is participation in the nationwide television series - with potential for an impact nationally. Television however, was not a magic bullet which children could dissolve all power hierarchies with. While they were able to articulate alternative agendas, voice their concerns and seek to influence community ideas and practices, without sufficient support from local allies, they could be vulnerable to intimidation and harassment. Moreover, their potential to mobilise and effect social change was 
undermined by structural factors, which they neither had the power nor resources to challenge. For example, while values regarding girls' education could be addressed, it was more difficult to address the underlying factors influencing parents' decisions to withdraw girls from school (high cost of education, poverty, minimal rewards for formal education).

It follows that while children can play a pivotal role as advocates for social change through challenging values, norms and beliefs, it is more difficult for them to disrupt behaviours and practices of the older and younger generations when there are structural impediments. In the context of persistent poverty and political repression of citizen voices demanding rights, many of the impediments to change lie not in the realm of culture but political economy. It is an area where children's agency has been of limited impact. It is questionable how much agency can be exercised in the IGT of human and social capital when they are influenced by power dynamics and relations, over which the individual has only limited control. The demise of the gender contract in practice but not in ideology is also likely to increasingly influence the opportunities for disrupting the gendered nature and content of IGT.

\section{Notes}

1 Trained field staff undertook a series of semistructured interviews with some of the children in August 2008 as part of the internal evaluation for the project. Transcripts of these interviews and staff observations provided insight into the children's perspectives on their roles and positions in these

\section{References}

Greenstreet, Miranda and Banibensu, R.A. (1997) 'Cross-generational Knowledge Transfer on Reproductive Health Among Women in Ghana', in Wendy Harcourt (ed.), Power, Reproduction and Gender, London: Zed Books

Moore, Karen (2001) Frameworks for Understanding the Inter-generational Transmission of Poverty and Well-being in Developing Countries, CPRC

Working Paper 8, Manchester: Chronic Poverty Research Centre

Mumtaz, Khawar and Rauf, Fauzia (1997) 'Interand Intra-generational Knowledge Transfer and Zones of Silence Around Reproductive Health, in Sunnakhi', in Wendy Harcourt (ed.), Power, Reproduction and Gender, London: Zed Books

Parrenas, Rhacel (2001) 'Mothering from a Distance: Emotions, Gender, and Intergenerational Relations in Filipino Transnational Families', Feminist Studies 27.2: 361-90

communities. Interviews conducted with women and adolescent girls in one poor urban squatter settlement of Cairo provided additional insight into some of the dynamics of intergenerational transmission of gendered ideas and realities.

2 Names throughout the paper have been changed.

Phalet, K. and Schönpflug, U. (2001) 'Intergenerational Transmission in Turkish Immigrant Families: Parental Collectivism, Achievement Values, and Gender Differences', Journal of Comparative Family Studies 32.4: 489-504

Putnam, R. (1993) Making Democracy Work: Civic Traditions in Modern Italy, Princeton: Princeton University Press

Woolcock, Michael (2002) 'The Place of Social Capital in Understanding Social and Economic Outcome', www.oecd.org/dataoecd/ 5/13/1824913.pdf (accessed 23 October 2008)

Woolcock, M. (2000) 'The Place of Social Capital in Understanding Social and Economic Outcome', paper prepared for an international symposium on The Contribution of Human and Social Capital to Sustained Economic Growth and Well-Being, Quebec City, 19-21 March 